\title{
US-China Relationship: Recommendations on US Outreach to China Through the Rhetoric of Soft Power
}

\begin{abstract}
Shengyi Zhang ${ }^{1 *}$
${ }^{1}$ The Hotchkiss School, Lakeville, 06039, U.S.

*Email: szhang22@hotchkiss.org

ABSTRACT

This paper proposes possible ways to improve the US outreach to China, given that the diplomatic relations between the two countries are experiencing an unprecedented downturn. The report contains two major parts. The first part reviews the current state of the relations with an exploration of the US image in China and the rest of the world, discussing its strengths and weaknesses that should later be considered when conducting foreign policies. The second part offers four recommendations to improve the US image in China through the enhancement of its soft power, including improvements on the use of Chinese social media, city diplomacy, and cultural and educational exchange.
\end{abstract}

Keywords: US International image, national brand, Chinese social media, Los Angeles and China,

“American Education Dream”, cultural exchange.

\section{INTRODUCTION}

On July 27, 2020, the American flag was lowered one last time at the US consulate in Chengdu, China. The closure of the consulate, in response to the closure of the Chinese consulate in Houston a few days earlier, marked a downturn in connections between the two countries as well. China had long loomed large in the political discussion in the US, and then emerged as a live issue for the presidential election year, unfortunately, that was further exacerbated by the recent COVID-19 pandemic. On the Chinese side, the US, too, has been attracting historically high levels of negative sentiment in recent years. This paper will explore the current state of the relationship between the US and China and the public diplomacy steps that the US could take to contribute to the amelioration of the relations, specifically through better use of social media, strengthened educational ties, city diplomacy, and cultural exchanges.

This paper emphasizes that neither country owns a monopoly of the responsibility for the escalation of the tension. The governments' responses towards each other around issues such as the pandemic and human rights are more like symptoms than the true sources of the downturn in relations. Other than those issues, China has a positive perception of the US, overall. The Chinese public admires US innovation, higher education, and development.

However, the US must be aware of the severity of the growing negative perceptions of Chinese people towards it. Before carrying out the diplomacy mission, the US government must improve upon its listening skills if it is to restore its reputation in China or, for that matter, in the rest of the world.

Looking ahead, the paper argues that both the US and China will need to take steps to enable the improvement of the bilateral relationship. For the US, the paper offers four recommendations to improve its national standing in China, mainly revolving around the enhancement of soft power. First, the US needs to take a critical look at its use of Chinese social media as a platform for diplomacy. The US embassy in China needs to understand that the high levels of on-line activity do not necessarily equate to a meaningful or positive connection with the Chinese public. The paper suggests that the US could use Douban, another Chinese social media platform but more nichefocused than others, to build deeper connections with targeted audiences, instead of just the general public, through culture. Second, the US needs to stop the elimination of educational exchanges and liberalize the immigration policy for people of Chinese origin. The US 
should learn how to maintain its last remaining soft power lever in China, the "American Education Dream". Third, the US should work at the city level and specifically keep nurturing the existing special relationship between Los Angeles and China in order to strengthen the national ties. Educational programs and film diplomacy will be effective tools to bring the two cultures together. Lastly, this paper recommends a crosscultural approach through Broadway theatre. "Love" is a universal language that transcends cultural boundaries. Broadway could adapt classic Chinese love folktales into American musicals, and tour in the US and those cultural cities in China, bringing Chinese culture to the US and introducing American theatre to the performing arts market in China.

\section{APPROACHING THE "TIPPING POINT"}

In recent years, the deepening social, economic, and diplomatic ties between the US and the People's Republic of China have been tilted apart. The relationship between the two countries has reached a "tipping point" [1], which can be attributed to a myriad of factors. These factors can essentially be summarized in the following areas: regional security, international influence, and ideology. Both sides are dissatisfied with the status quo of security interests in Asia; As China's national power grows, there has been fear on both sides regarding the possibility of threat coming from the other side; the overt distrust and criticism in each other's political system or model have further sharpened the rivalry situation the world is witnessing now. Sun Tzu once remarked, "Know your enemy and know yourself." [2] Now, to enable a peaceful coexistence and meaningful bilateral relationship relinquishing the concept of "war", the US should know the partner by taking steps to listen and to truly understand China, eliminating existing misperceptions and improving its profile.

First of all, in contrast to many Americans' perceptions, China views the US as prosperous, innovative, and highly developed with admiration. A survey conducted by the Eurasia Group Foundation in 2019 finds that the Chinese were generally positive about the US, with 41 percent responding they have a "somewhat " positive view of the country and 17 percent saying they had a "very" positive view. At the time, only 9 percent were "very" and 8 percent "somewhat" unfavorable toward the US [3]. On a global scale, in 2020, the US scored 60.5 in the Global Innovation Index issued by the World Intellectual Property Organization (WIPO), remaining its third position worldwide [4]. Additionally, according to the 2020 Best Countries Report, the US ranks first place in education across the world [5]. And just like many other nations, China shows great respect for American financial and technological wizardry along with its open-mindedness and diversity, resulting in their high pursuit of American education. Since 1970, the number of Chinese international students studying in the US has experienced a surge, from less than 1000 to approximately 370,000 in 2019 , comprising the largest percentage of the international students studying in the US [6]. A decade ago, only the rich families could afford their children to pursue their US education dream. Over the years, more and more middleclass families are finding ways to help their kids to achieve their higher education goals. Up until now, it's safe to say that the largest strength the US possesses in China is its education, or its ability to appeal to the people, regardless of their family backgrounds. It has always been the leading destination overseas for education.

However, the Chinese view towards the US has indeed grown generally less favorable since 2016, the start of the Trump administration. That is not to say that President Trump owns a monopoly of responsibility for the downturn in relations, but the failure to recognize and reflect on the other side of China's viewpoints will certainly hurt the American interests. During the four years of administration, the growing conceptual differences escalate and become more revealed. In the same survey mentioned above but conducted in 2020, the results showed a drastic rise in Chinese unfavorable sentiment towards the US with 28 percent of respondents reporting a negative view, up from seventeen percent in 2019. This tendency largely results from the increased exposure the Chinese gets on American democracy this year, but mainly with negative perceptions: China views the US as a "chaotic", "intrusive", and "unsafe" country. The popular perception that China aims to claim itself as the regional hegemony and expel the US out of East Asia is incorrect. Just like Wangyi, the foreign minister of China, claimed that "We respect the traditional influence and immediate interests of the US in the Asia-Pacific," China, in fact, welcomes the US to play a constructive role in regional affairs [7]. However, they believe that the real issue lies in the extent to which the US manages those affairs and the lack of understanding of Asian culture, history, and values. According to the same survey, $70 \%$ of the Chinese respondents believe that the US should "focus on flaws in its own political system instead of focusing on the political systems of other countries," with most wanting a "less assertive" US foreign policy. Contrary to the American values, which emphasize "independence" and alert people to the "law of the jungle", the Chinese culture has always highlighted the importance of "harmony" and "sharing". China understands that it's difficult to achieve a position comparable to the US with its limited hard power and soft power. But, even if it is on par with the US someday, it would believe in multipolarity and equal opportunities for countries to grow and exert influence, instead of hegemony [8]. As a myriad of external and internal conflicts being laid out almost simultaneously, China, along with the rest of the world, further acknowledges the aggressive and unpeaceful image: The US ranked 121th out of 163 countries in the 2020 Global Peace Index. Although foreign publics admire U.S. innovation, higher education, and diversity, they do not always fall under illusions about U.S. shortcomings, be it healthcare or social chaos. In 2020, the US performance in response to the COVID-19 sparked unfavorable views from the world. In a study conducted by the Pew Research Center on China's international image and the international image of the US, in all countries except Japan and the US 
itself, countries rate China more positively than the US in handling the pandemic. Regarding the recent Black Movement taking place across the US, the general public and state media of China have shown deepened doubts on the alleged democracy with accusations. The handling of the protests also received criticism from its historical allies, like the European Union, and human rights groups. In short, the US should be aware of its suffering image from the perspective of not only China but also the rest of the world.

\section{A BETTER USE OF CHINESE SOCIAL MEDIA}

To alter the declining national standing in China, spreading American culture through a stronger presence and closer connection with the public on Chinese social media would be a good place to start. Just like many other foreign embassies, the US has opened an account on Weibo--the most popular social media platform in China -- to reach out to the Chinese public. However, the embassy lacks the ability to influence its audience despite having a high level of interactivity. For example, if looking at the comment section under "Today in History", which is a non-political topic, more than half of the comments were negative; the netizens are always able to find ways to politicize the content with nationalistic sentiment [9]. To address the issue, the US embassy in China could open an official account on Douban, a more specialized and topic-oriented social media platform that connects people (mainly degree holders with middleclass lifestyle) who are passionate about books, music, cinema, and culture. Users connect according to their interests by joining different "groups" with specific themes and participating in online promotional events. The embassy could initiate a group regarding

American culture and create specific themes such as US literature, US top colleges, US South vs North, American people vs Chinese people, etc. For each related theme, the embassy could launch interesting discussion questions such as "Do you think tipping culture is necessary?" "What are some of the good/bad American movie adaptations?" and "Describe a personal experience in the US that differs from your prior knowledge" while providing context and its own opinions on the top for the community to see. Other ways to engage the users are conducting opinion polls on feed preference, posting short blogs to share book, movie, or music reviews, and holding online events monthly such as poetry translation competition for American poems to bridge the two language cultures. The bottom line is that the embassy needs to interact with the audience on a consistent basis, instead of merely outputting information without taking in the public opinion. Although Weibo serves as an important platform for diplomacy, the unique features, users, and interest-based nature of Douban allows the US to appeal its culture to the Chinese online public in a more rational and friendlier environment while establishing an intimate connection with the targeted audience, which can later be expanded into a large community.

\section{NO MORE EDUCATION DECOUPLING}

While utilizing the right online channel to influence the public through culture, the US should stop the racial profiling of the Chinese international students and researchers and eliminate the imposed restrictions to secure its educational brand, which is one of the few remaining vestiges of leverage it holds over China. This year, the US has accelerated its educational decoupling with China through the following ways: The elimination of The Peace Corp program and Fulbright program, the suspension of entry of a large number of Chinese graduates and researchers, and the limitation imposed on Chinese graduate students to major in STEM fields. These decisions, which are being viewed as racism, could cause the number of Chinese students to plummet. The US needs to understand that if it no longer welcomes them, China will, with all its attractive benefits. In addition to the loss of the Chinese international students, researchers, and scholars, the US is also losing the support of those Chinese intellectuals who essentially act as cultural ambassadors of the US living in China, further ruining its educational brand, which is not only wellknown for the quality-education but also its diversity and inclusion. Most importantly, the US should realize that the loss of the Chinese talents equates its loss of learning as well. The act of blocking them away from US education is also cutting off its channel to listen, to learn, to better understand China, all of which are the primary steps to build a strong diplomatic relationship. What the US should do instead is to liberalize Chinese immigration and ensure each of them with a college degree, a green card, or work permit without arbitrary visa restrictions to encourage a welcoming environment. National security and interests should be protected, but there are certainly better ways to regain confidence and competitiveness than educational decoupling and racial profiling.

\section{LOS ANGELES: THE "EPICENTER" OF US-CHINA RELATIONSHIP}

Besides the foreign ministry, the US should also conduct bilateral activities to ameliorate the relationship on a local level. Los Angeles could be a gateway for partnerships in the education and entertainment industry as a city that already has a unique relationship with China for more than 150 years. From the California Gold to the Central railroad labor to the end of WWII, during which immigration laws to Chinese began to relax, Los Angeles County has experienced massive waves of Chinese immigration. As of 2019, Chinese accounts for $32 \%$ of the Asians in Los Angeles County with an estimation of 469,752 people, more than any other county in the US [10]. The large base of population with the close connections forged in the past have helped foster the educational and business ties between the city and the Chinese descendants. Locally, no other state has attracted more Chinese students than in California. There are roughly 161,693 Chinese students enrolled in schools in California in 2019, making up the largest percentage of international students among all the Asian countries. Los Angeles Country by itself has 20,000 Chinese students 
attending universities [11]. Many universities in Los Angeles, such as USC and UCLA, invest abundant time and resources to achieve the goal of better understanding China with courses, institutes, study centers, and exchange programs related to the Chinese language and culture. Multiple schools across Los Angeles County also offer them elite training programs for provincial government professionals. After those Chinese students become alumni and develop successful careers, they will serve as essential links for collaborations on global issues such as climate change and disease-fighting along with useful associations for Chinese and Chinese Americans such as Asia Society and American-Chinese CEO Society (ACCS). In addition to educational and personal ties, Los Angeles and China are also on the leading trajectory of two-way investments in the entertainment industry. Take Hollywood as an example of the medium for public diplomacy. Due to China's huge media market and contribution in its box office, Hollywood studios increasingly have Chinese audiences in mind, resulting in a handful of joint ventures and co-productions films, including "Kungfu Panda", the first movie with both Mandarin and English versions. In future co-productions, Hollywood can feature other classical Chinese legends such as Shui Hu Zhuan (Water Margin) and Hong Lou Meng (Dream of the Red Chamber) in animated form. Since the youth Chinese population generally embrace American culture and the Americans are fascinated with heroism, the cross-cultural collaborations on film making will enable both sides to update narratives of one another and learn about each other's culture and development, which is particularly helpful for the US to enhance its impression on China. Considering the profound educational and investment ties, Los Angeles should be treated as a propeller and stabilizer for the US-China relationship.

\section{CULTURAL EXCHANGE THROUGH BROADWAY}

The US soft power has long been its exceptional strength to influence the world but has become increasingly uncertain with the growing negative impression it has made on China.

China's image, too, has faced a declining trend primarily due to its trade and ideological conflicts with the US. To change the perception of each other, the US and China should join together and organize cultural events that enable the exchange of ideas: A partnership between Broadway and Chinese tragic love folklores. The current state of cultural diplomacy is more of aonesided one; while the Chinese can easily embrace the American culture, it is not quite the other way around. Although the Confucius Institutes have achieved some success with its aim to promote Chinese language and culture, it is still ineffective in appealing to the American general public since it originates from a completely different system of values and beliefs. And despite the diversity and profoundness in its culture, China lacks the influence to export that one particular culture to the US and the world. Therefore, China needs a medium coming from a dominant culture to project its own, which the US can provide. Incorporating the two cultures into one another would be a way to shorten the distance between them while also maintaining the originality of each. The Broadway team, which has already started its investment in Asia, could offer productions adapted from the bestknown Chinese classic love folktales, such as The Legend of White Snake and Butterfly Lovers, and tell the beautiful yet tragic stories in music with the infusion of both Chinese and Western musical elements. Love, a universal emotion experienced by all cultures, manifests itself in various ways, influenced by different cultures. By presenting the story on stage through the form of a Broadway musical, the American audience can have a new conception of the Chinese version of "love", including how and what they feel, think, and value in romantic relationships. The play allows them to develop a deeper understanding of Chinese history and culture through the incorporations of their traditional clothes, foods, architectures, martial art (Chinese love folktales often contain the element of martial art), and daily lives in ancient China. The visuals on the stage will certainly make a deeper impact on the public than merely having them sit down and listen to tedious lectures about the culture in a classroom. The live performance can emotionally engage the audience by making them feel as if they are experiencing the lives of the characters in ancient China. For the Chinese, they are also given a new perspective to American culture through the musical theatre experience, which is distinct from the modern pop culture they've been embracing. The play will have two casts, one with all Chinese actors and the other with all American actors. The production team will use different casts and language depending on where the show takes place. Besides places across North America, the production will be touring in nine cities in China: Beijing, Shanghai, Hangzhou, Nanjing, Xian, Chengdu, Guangzhou, Wuhan, and Shenyang, all of which are toptier cities in different parts of China with great cultural tourism attractiveness. The inaugural performance will take place in Hangzhou, the city from which those love folktales originate, and the show will run for about a month in each city. This cross-cultural collaboration will result in the introduction of American theatre to the performing arts market in China and the outstanding cultural dramas of China to the Americans.

To evaluate if the event is worth the support for improving the US-China relationship, both short-term and long-term effects will be assessed. For the intermediate impact, the first-week attendance and box office can be the most direct indicators to measure the success of the event. Chinese authoritative theatre, novel, and drama critics should also be invited to watch the show, and their reviews will be an important factor that determines the longevity of the event from a professional perspective. At the same time, surveys that collect demographic information including the level of education, age, and gender can be distributed online to the Chinese public to see if their experiences are positive with rating and open-ended questions. The production team should also keep track of Douban, the social media app previously mentioned, as a credible platform for reviews due to its large user base and high interactivity. If the first-week reactions are generally positive, it 
suggests the public's initial acknowledgment of the event and potential curiosity towards this field of American culture. The same evaluation methodology applies to the shows in the US, too, but also asking people about their thoughts on the similarities or differences between romance in China and that in the US. Towards the end of the tours, an analysis of public opinion should be conducted by recollecting the survey data and categorizing them into different demographic categories. The ideal scenario would be that the show appeals to a wide range of Chinese audiences. Music charts could be another index to measure the effectiveness of this virtual cultural exchange, though not necessary. In 2015, Hamilton's debut at 12 on Billboard 200 was considered a phenomenon that led to a change in the music culture. If any of the English cast recordings from this crosscultural production ever enter the US chart, it's a manifestation of a successful promotion of Chinese culture.

Admittedly, it's difficult to see the development of a comprehensive interest in each other's culture if only by employing the methods mentioned above. However, any form of cultural exchange takes time to harvest. There are various ways that indicate the fulfillment of the event (assuming there will be more Chinese folktales adapted by Broadway following the first collaboration). To verify if similar events have created a positive impact on the US towards the Chinese culture in general on a longer-term, here are some of the common ones that could be expected: The increase in the number of Americans to study Chinese language and literature, the rise in popularity of Chinese historical drama, growing translations and stage or screen adaptations of classic Chinese novels, growing recognition of Chinese classic stories to an extent where it is often brought up during conversations about Asian culture, etc. Since it's quite hard to generate a tremendous interest in the American culture by just watching a few shows, Broadway can launch summer programs related to American theatre and musicals in China to prompt further interests. Then, the cultural impact brought by the US can be measured through the popularity of these programs over time while promoting them to more people. Meanwhile, the trend of the number of Chinese audiences going to Broadway Theatre in the US can also assess the effectiveness of this form of cultural exchange.

\section{CONCLUSION}

Hard Power is too blunt an instrument for a multipolar world where the other countries, especially China, continue to rise. In this globalized world in which everything is interconnected, no one wants to see governments using missiles and bullets as a way of engagement. Remember, one single policy can involve the interests of countless groups across the world. Yes the US should continue to be aware of the growing strength and aggressiveness of China, but there are better remedies than shutting down educational programs and closing the door to expel the migrants who come here bring invaluable knowledge and information. In order to enhance the national image and increase the efficacy of exerting influence on China, the US must learn to utilize its cultural soft power for diplomatic purposes. Some potential approaches this paper recommends include accommodation of Chinese social media, embracement of Chinese people living in the US, amelioration of the LA-China bonds, and promotion of cultural and educational exchange in an effort create mutual understanding between the people. Still, although we are at the stage where the countries can easily reach a broad agreement on a certain issue, it requires strong executive actions and deep, meaningful conversations to prevent a consensus from collapsing.

\section{REFERENCES}

[1]. Lampton, D. M. (2015). The tipping point: Can we amplify what we have in common. Horizon, (4). https://www.cirsd.org/en/horizons/horizonssummer-2015--issue-no4/the-tipping-point---canwe-amplify-what-we-have-in-common-

[2]. Sun, T. (1994). Attack by stratagem (L. Giles, Trans.). In T. Sun (Author), The art of war. Project Gutenberg. https://www.gutenberg.org/files/132/132-h/132h.htm

[3]. Panda, A. (2020, April 19). Survey: Chinese report less favorable views of US democracy. The Diplomat. Retrieved December 31, 2020, from https://thediplomat.com/2020/04/survey-chinesereport-less-favorable-views-of-us-democracy/

[4]. Dutta, S., Lanvin, B., \& Wunsch-Vincent, S. (Eds.). (2020). Global innovation index 2020: Who will finance innovation (13th ed.). Library Public Services Office, Cornell University. https://www.globalinnovationindex.org/analysiseconomy

[5]. Best countries for education. (n.d.). US News. Retrieved January 1, 2021, from https://www.usnews.com/news/best-countries/besteducation

[6]. Kopf, D. (2020, October 28). Data show Chinese students are steering clear of the US. Quartz. Retrieved December 31, 2020, from

https://qz.com/1923859/chinese-students-aresteering-clear-of-the-us/

[7]. Wang, Y. (2013, September 20). Toward a new model of major-country relations between China and the United States [Speech transcript]. Retrieved December 31, 2020, from https://www.brookings.edu/events/toward-a-newmodel-of-major-country-relations-betw een-chinaand-the-united-states/

[8]. CGTN. (2020, July 9). Stay on the right track and keep pace with the times to ensure the right direction for China-US relations [Address video]. https://www.youtube.com/watch?v=8NuIQAZj_7g

[9]. Jiang, Y. (2016). The use of Chinese social media by foreign embassies: How "generative 
technologies" are offering opportunities for modern diplomacy. In Y. Jiang (Author), Making publics, making places (pp. 145-162). University of Adelaide

Press.https://www.jstor.org/stable/10.20851/j.ctt1t 304qd.14?seq=1\#metadata_info_tab_content
[10]. ACS demographic and housing estimates. (2019). United States Census Bureau. Retrieved January 1, 2021, from https://data.census.gov/cedsci/table?g=0400000US 06_0500000US06037\&tid=ACSDP5 Y2019.DP05

[11]. Guerra, F. (2014, June). Growing together: China and Los Angeles County. Retrieved December 31, 2020, from

https://laedc.org/wp-content/uploads/2014/05/2014Growing-Together-China-and-LA-Co unty.pdf 